\title{
DECISION MAKING APPROACH TO PREFER ROUTE REPAIR TECHNIQUE IN AODV ROUTING PROTOCOL OF MANET
}

\author{
Shikha Patle ${ }^{1}$, Purushottam Kumar ${ }^{2}$ \\ ${ }^{1}$ Research Scholar, Dept. of CSE, Oriental University, Indore (M.P), India \\ ${ }^{2}$ Assistant Prof., Dept. of CSE, Oriental University, Indore (M.P), India
}

\begin{abstract}
MANET is a dynamic environment of mobile nodes and suffers link failure problem i.e. due to node mobility, loss of energy, node failure etc. To overcome the broken link problem, initiated route repair mechanism. The suggested two route repair techniques are used to repair the broken link of the network. Either the routes can be repaired by re-establishing a new route starting from the source node or the routes can be repaired by the node that detects the link break along the path. The mechanism is proposed to prefer route repair techniques on the basis of decision. According to this approach, the different route repair values are defined on the basis of the active path of network and calculate the link break value of the network for finding in which location the link break is occurring to initiate route repair mechanism. For implementation, apply the proposed approach on an AODV routing protocol and check which route repair techniques are used. Simulate the results on the basis of different parameter i.e. sent data packets, received data packets, dropped data packets and energy consumption.
\end{abstract}

Keywords: MANET, AODV Routing Protocol, Source Repair, Local Repair

$* * *$

\section{INTRODUCTION}

The mobile ad-hoc network (MANET) is an infrastructure less wireless ad-hoc network. It is self organized and autonomous network of mobile nodes connected by wireless links and does not depends on any centralized access point or base station. Each node in the network may act as a router or as a host and is free to move independently. In MANET communication between mobile nodes is possible, when they are in range of each other. The mobile nodes are variable in nature and the network topology may be configured in an arbitrary manner and change dynamically. Thus the variable topology and node mobility may cause the link failure problem. MANETs are being used in many application scenarios such as: military and battlefield, search and rescue operation, disaster recovery, public safety and personal area network etc. [1].

MANET is a self creating network of mobile nodes and suffers link failure problem due to many reasons such as: node mobility, battery power off and node failure etc. Thus one of the main challenging issues in MANET routing protocol is how to deal with link failure problems and how to repair this link in this situation [2].

Ad-hoc on demand distance vector routing protocol is used to repair the broken link. It is an efficient reactive routing protocol for Mobile Ad-hoc Networks with dynamic topology and creates a path to the destination when required. AODV also creates the routing table during data transmission and maintain the routing table information about the active route of the network [8]. AODV uses two route repair approaches for repair the broken link. Either the routes can be repaired by re-establishing a new route starting from the source node is known as the source repair approach or the routes can be repaired by the node that detects the link break along the path is known as the local repair approach [9]. Instead of the challenges is how to find that which route repair technique is used to repair the broken link.

In this paper, we define a mechanism for selection of route repair techniques on the basis of different route repair values for different network scenario. The simulation result clearly identifies that which route repair techniques are used in the different cases of link break and the network performance is calculated on the basis of different network parameters.

\section{OVERVIEW OF AODV ROUTING PROTOCOL}

AODV Ad-hoc On Demand Distance Vector Routing Protocol is an efficient reactive routing protocol for Mobile Ad-hoc Networks with dynamic topology and creates a path to the destination in an on demand manner by broadcasting RREQ message. It also creates the routing table during transmission and maintains the routing table information about active route.

The working of the AODV routing protocol is described as follows:

\subsection{Route Discovery}

Route discovery is initiated when the source node wants to send data packets to the destination node and there is not valid route information in the routing table. The source node initiates the new route discovery process by broadcasting the Route Request Message (RREQ) and waits for Route Reply Message (RREP). 
Ad-hoc On Demand Distance Vector Routing Protocol uses three types of message for route discovery.

\subsection{Route Request Message}

The source node forwards the RREQ message throughout the network for finding a new active route to the destination. The RREQ message contains the following fields < source_add, source_sequence number, Broadcast_id, destination_add, destination_sequence number and hop_count $>$. The pair of source_add and broadcast_id identifies the new RREQ message and broadcast_id is incremented every time when the source node initiates a new route request message. The destination node and neighbour node respond the RREQ message by generating the RREP message.

\subsection{Route Reply Message}

During the communication, if destination node or other intermediate node receives the RREQ message then this node respond by sending the corresponding Route Reply Message (RREP) back to the source node and update the routing table information. The RREP message contains the following fields: < source_add, destination_add, destination_sequence number, hop_count and life_time >.

Route Error Message: During the communication, if any nodes are moved out of topology then the node generates the Route Error Message (RERR) and sends back to the source node and other intermediate nodes.

\subsection{Route Maintenance}

Every node broadcasts the hello message for local connectivity and the freshness of the route.

\subsection{AODV Route Repair Techniques}

The suggested two routes repair techniques are used in AODV routing protocols to repair the broken link as described below:

\subsubsection{Source Repair}

The node that detect the link break and which is nearest to the source node sends a route error message back to the source node. Then the source node initiates new route discovery process to destination node through rebroadcast the route request message to other intermediate nodes of the network. If the destination node receives a RREQ message from source node, then this node responds the RREQ message by resending the RREP message back to the source node within the limited period of time and providing the new route for transmission.

\subsubsection{Local Repair}

The node that detects the link break and which is located far away the source node can locally try to repair the link for initiating new route discovery to destination node for rebroadcasting RREQ message. If the destination node receives the new RREQ message then it generates the corresponding RREP message for repairing node. The node that initiates the local repair mechanism receives the RREP message from destination node and provides the new route for transmission.

\section{RELATED STUDY}

According to the paper [8] when the link break is occurring in an active path and the node that detects the link break locally tries to repair the route. This node broadcasts the Forward Ant (F-Ant) message to other nodes for searching active path to the destination. After one or two hops the FAnt found the required nodes that have an active route to the destination. The next new node generates Backward Ant (BAnt) message and forward back to the repairing node within the allotted time. The new route is available and this route is used for transmission. If the repairing node does not receive the B-Ant message within the time, it generates the REER message back to the source node.

According to the paper [9] author defines the route repair technique for Ad-hoc On Demand Distance Vector (AODV) routing protocol. Author proposed a fixed and absolute range of threshold parameter for the selection of which route repair strategy is to choose.

The link break location parameter Llb as follows:

$\mathrm{Llb}=$ hop index of the broken link / total number of hops in the path.

For examples: Author assumption 5 hop paths exist between source node to the destination node and the link break has happened by node 2 .

In this scenario link break calculation is as follows:

$$
\mathrm{Llb}=2 / 5=0.4
$$

Where: 2 defines the hop index of broken node Total number of paths from source to destination is 5 .

According to the approach, threshold (Tlr) value is 0.5 means that the link break has happened is more than half of the path then local repair is invoked, otherwise source repair will perform. Above example shows link break location is 0.4 and Threshold is 0.5 , according the approach Llb is less than Tlr ( Llb < Tlr) so perform source repair.

In MANET one of the main challenging issues is routing, due to the node mobility, dynamic changes of topology, node power failure, bandwidth constrained its link failure occurred [10]. In this paper author analyses the different On Demand Routing Protocol on the basis of the packet delivery ratio, throughput and delay to propose the solution of link failure in different situations. If a source node moved out of topology, then it finds a new route to the destination using the new route discovery and updates the routing table information. When link break has occurred by an intermediate node, then the local repair procedure is used to repair the path. 


\section{PROPOSED METHODOLOGY}

The mechanism is proposed to prefer route repair techniques. According to the approach, calculate the link break value of the network for finding in which location of that network the link break is occurring to initiate route repair mechanism.

The calculation of link break value for active route of the network is defined as the ratio of:

$$
\text { Lbv }=\text { Hi / Total Sum of hops }(\mathrm{Hs}-\mathrm{Hd}) /
$$

Where: $\mathrm{Lbv}=$ Link break value

$\mathrm{Hi}=$ hops index value of the broken link

$\mathrm{Hs}-\mathrm{Hd}=$ Sum of hops in the path

(Hs = Hop count of the source node and $\mathrm{Hd}=$ Hop count of the destination node)

The hop index value of the broken link is simply counting the number of hops starting from the source node to the broken node and the sum of hops in the path is the total number of hops from source to destination node along the active route.

For example: Consider the network scenario for link break calculation as shown below in figure 1 and figure 2 .

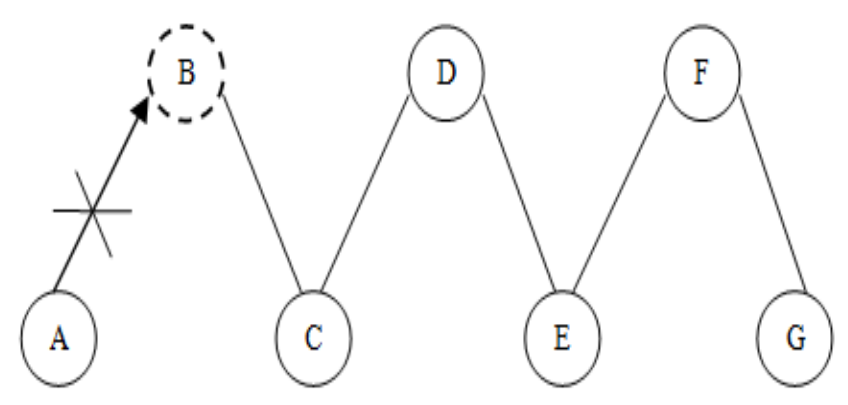

Fig 1 Link break calculation

Assuming node B is moved out of topology due to mobility. Then the link break value of this network is calculated as follows:

$$
/ \mathrm{Lbv}=\mathrm{Hi} / \text { Total Sum of hops }(\mathrm{Hs}-\mathrm{Hd})
$$

Where: Hop index value of node B is 1

Total sum of hops in the path from source to destination is 7

$\mathrm{Lbv}=1 / 7$

$\mathrm{Lbv}=0.142$

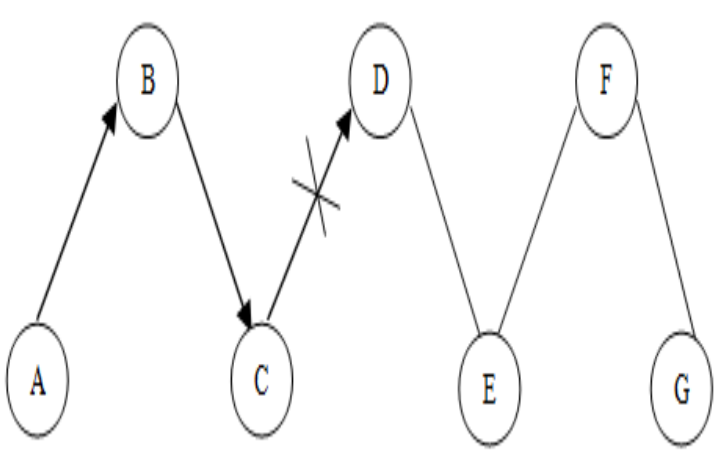

Fig 2 Link break calculation

Assuming node D is moved out of topology due to mobility. Then the link break value of this network is calculated as follows:

$$
\text { // Lbv = Hi / Total Sum of hops (Hs - Hd) // }
$$

Where: Hop index value of node D is 3

Total sum of hops in the path from source to destination is 7 . $\mathrm{Lbv}=3 / 7$

$\mathrm{Lbv}=0.428$

In the proposed solution, the set of different route repair values is also defined on the basis of the active path of network i.e.

One fifth part of the path $(1 / 5=0.2)$

One fourth part of the path $(1 / 4=0.25)$

One third part of the path $(1 / 3=0.33)$

Half of the path $(1 / 2=0.5)$

After the half of the path (0.5), the broken link is always repaired by the local repair approach because the half of the path is already covered by the node and at that time if the source repair approach is used then it takes more time for the new route discovery process. That's why after the half of the path local repair approach is always preferred as well as in this research work after half of the path any route repair value is not defined.

\section{SIMULATION AND RESULT ANALYSIS}

The proposed approach is simulated in network simulator (NS-2) considering some simulation parameters which are given below.

\subsection{Simulation Parameter}

Table 1 shows the different network parameters and its respective value.

Table 1 Simulation Parameter

\begin{tabular}{|l|l|}
\hline Parameter & Values \\
\hline Number of nodes & 7 \\
\hline Route repair values & $0.2,0.25,0.33,0.5$ \\
\hline
\end{tabular}




\begin{tabular}{|l|l|}
\hline Radio-propagation model & Two Ray Ground \\
\hline Antenna model & Antenna/ Omni Antenna \\
\hline Routing protocol & AODV \\
\hline Simulation area & 1000 X 1000 \\
\hline Initial energy in Joules & 100 \\
\hline Simulation time & 30 seconds \\
\hline Traffic type & TCP \\
\hline Channel type & Channel/ Wireless Channel \\
\hline Node speed & $30 \mathrm{~m} / \mathrm{s}$ \\
\hline
\end{tabular}

\section{RESULT ANALYSIS}

The result of proposed approach is analyzed by considering following network performance evaluation parameters.

\subsection{Performance Metrics}

The result is analyzed considering scenarios as shown above in figure 1. The scenario is simulating for node 1 , when in the case of node 1 link is repaired by the source repair approach. The graph of sent data packets, received data packets, dropped data packets and energy consumption of every node as generated.

\subsection{First Scenario}

Assume in the first scenario node 1 is moved out of topology and the link is broken between node 0 and node 1 , calculate the link break value and apply the proposed approach. The link break value is 0.142 , which is less than the route repair value 0.2 , as the link is repaired by the source repair approach and again data transmission is started from source to destination.

\subsection{Sent Data Packets}

After repairing the link again data transmission starts from source to destination and the total number of sending data packets is 298 by all the nodes as shown below in the figure 3.

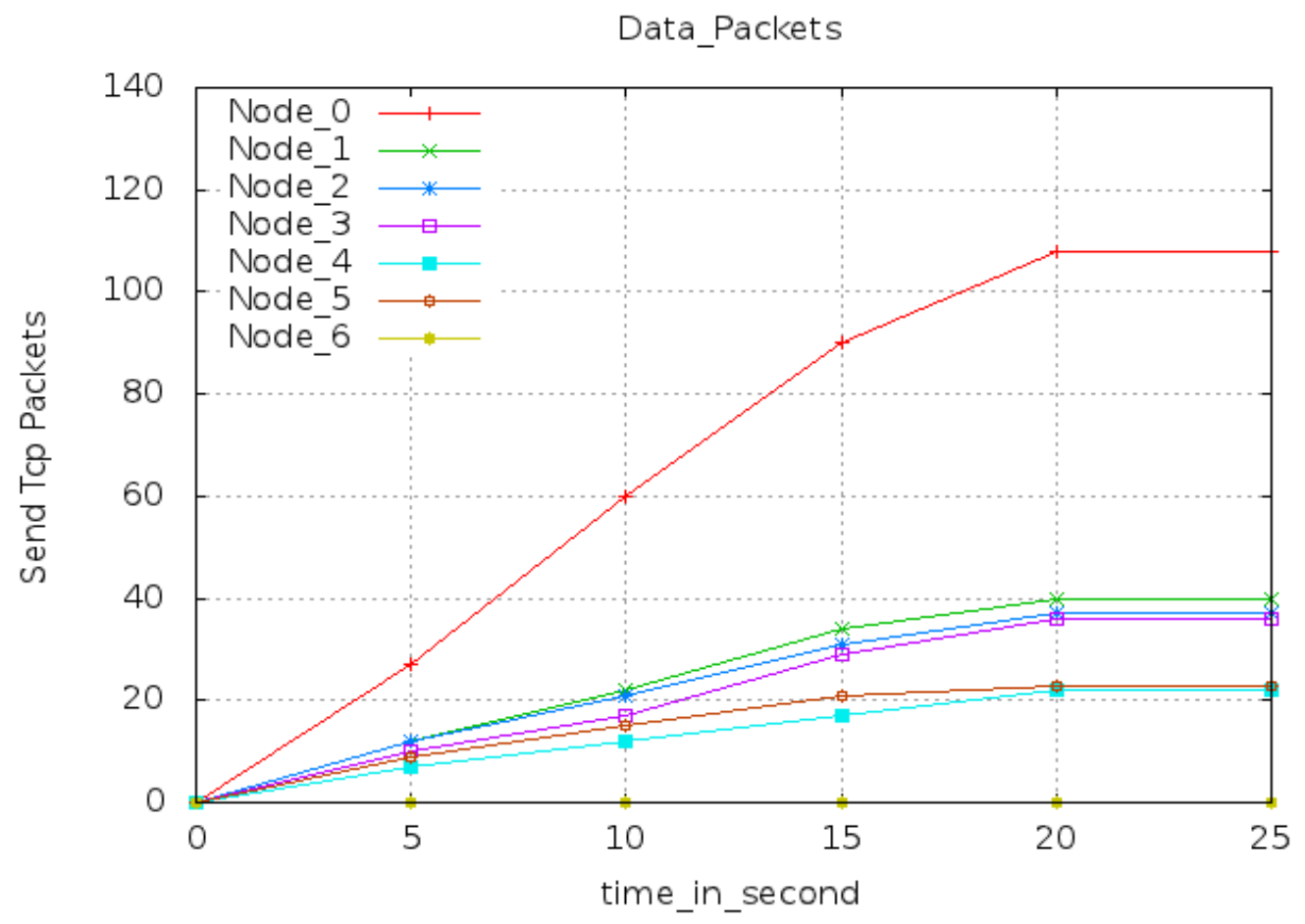

Fig 3 Sent data packets graph of node 1 for RRV 0.2

\subsection{Received Data Packets}

The total number of received data packets graph is shown below in the figure 4. This graph shows that total data packets received by all nodes are 263 . 


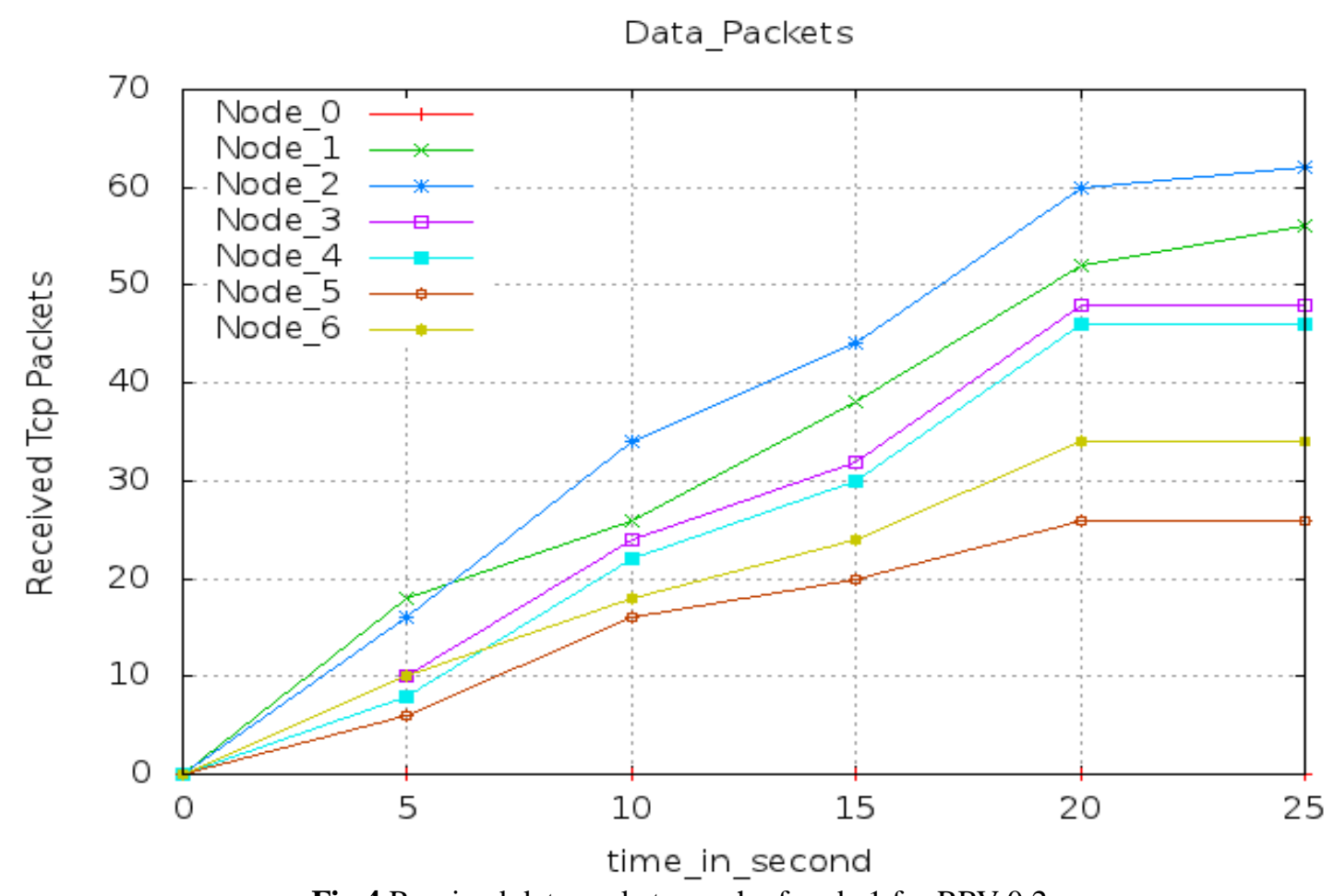

Fig 4 Received data packets graph of node 1 for RRV 0.2

\subsection{Dropped Data Packets}

During data transmission some data packets are dropped by node 0 , node 1 and node 2 as shown below in the figure 5 . This graph shows that the total 35 data packets are dropped.

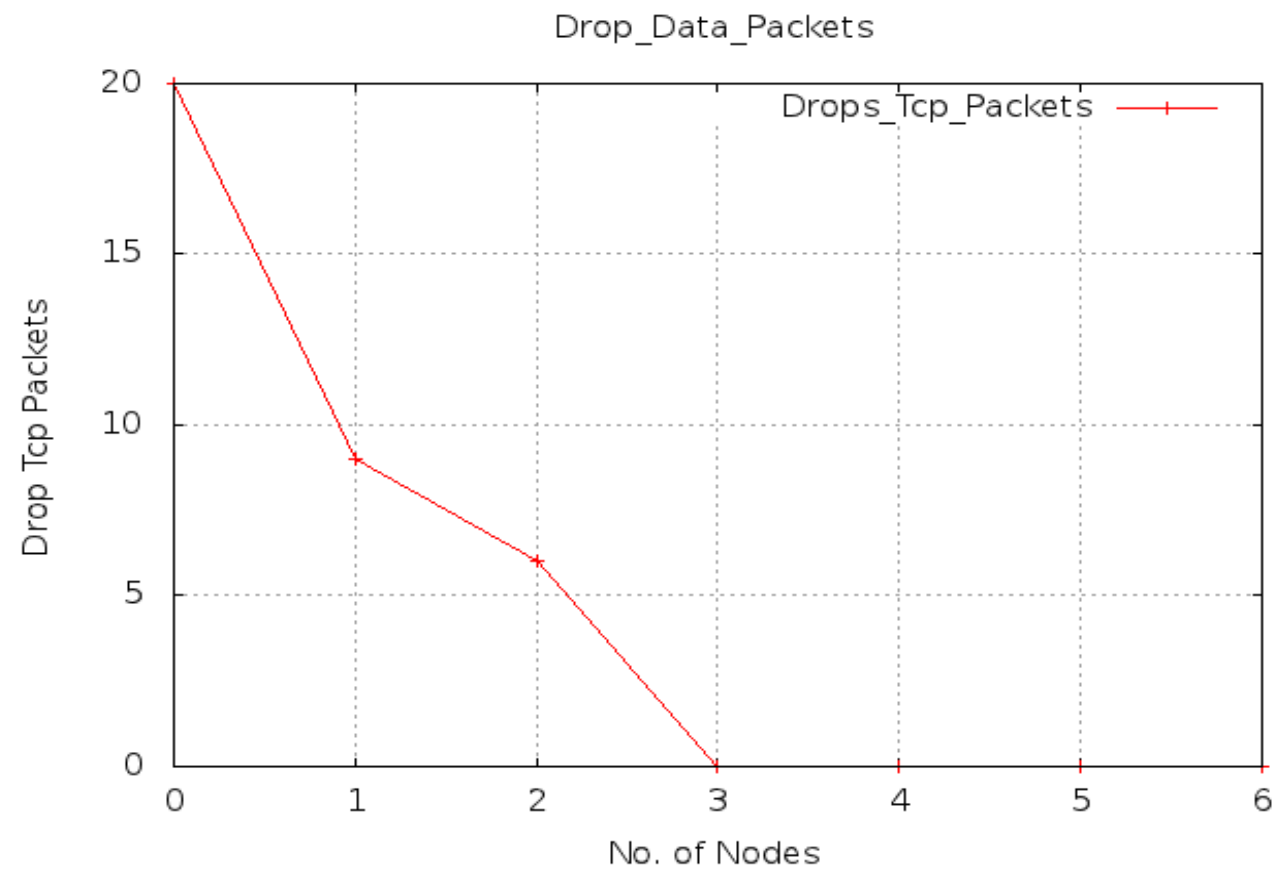

Fig 5 Dropped data packets graph of node 1 for RRV 0.2

\subsection{Energy Consumption Graph}

The energy consumptions graph of every node as shown below in the figure 6 . The graph shows that before simulation every node has energy of 100 joule and after the simulation every node consumes some amount of energy for sending RREQ and receiving RREP message. 


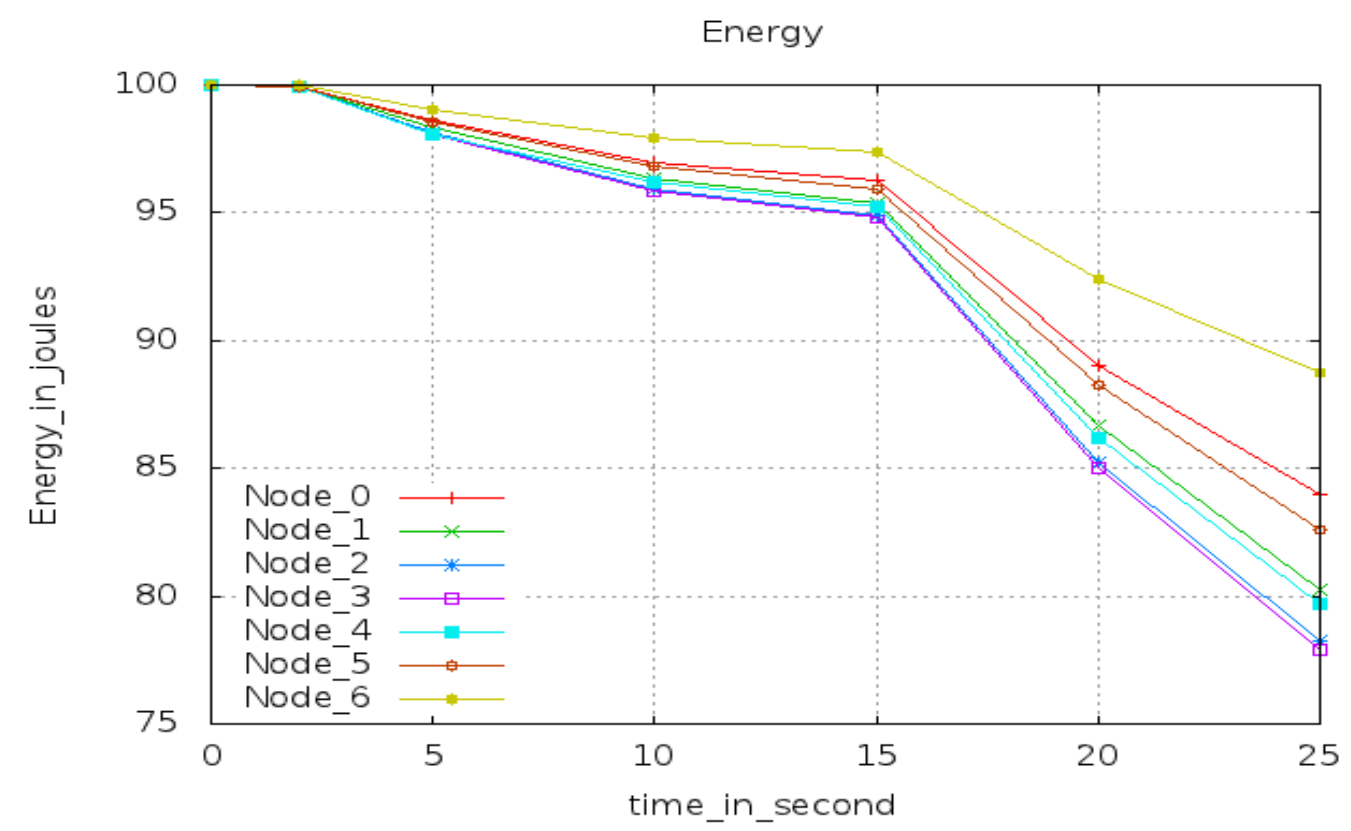

Fig 6 Energy consumption graph of node 1 for RRV 0.2

\section{PERFORMANCE EVALUATION}

To investigate the performance of the AODV routing protocol, we use the packet delivery ratio for comparison between the base paper result and the research work.

According to the paper [9], author use the range of fixed threshold value for selection of route repair strategy. The threshold (Tlr) value is 0.5 means that the link break has happened is more than half of the path so local repair is invoked, otherwise source repair will perform, but in the our proposed approach, we correctly identify the selection of route repair technique and improved the packet delivery ratio.

After analysis the result of proposed approach and paper [9] approach, we found the following route repair selection strategies as shown in the table 3.

Table 3 Route Repair Selection Method

\begin{tabular}{|l|l|l|l|l|}
\hline $\begin{array}{l}\text { Movin } \\
\text { Node }\end{array}$ & \multicolumn{2}{|l|}{ Proposed Approach } & \multicolumn{2}{l|}{ Fixed Threshold Value } \\
\hline & $\begin{array}{l}\text { Proposed } \\
\text { Mechanis } \\
\mathrm{m}\end{array}$ & $\begin{array}{l}\text { Route } \\
\text { Repair } \\
\text { Techniqu } \\
\mathrm{e}\end{array}$ & $\begin{array}{l}\text { Approac } \\
\mathrm{h}\end{array}$ & $\begin{array}{l}\text { Route Repair } \\
\text { Technique }\end{array}$ \\
\hline 1 & $\begin{array}{l}0.142> \\
0.2\end{array}$ & SR & $\begin{array}{l}0.166 \\
0\end{array}$ & LR \\
\hline 2 & $\begin{array}{l}0.285 \\
0.33\end{array}$ & SR & $\begin{array}{l}0.33> \\
.25\end{array}$ & LR \\
\hline 4 & $\begin{array}{l}0.571> \\
0.5\end{array}$ & LR & $\begin{array}{l}0.66> \\
0.75\end{array}$ & SR \\
\hline
\end{tabular}

Performance of AODV routing protocol on the basis of table 3 results as shown in the figure 7. 


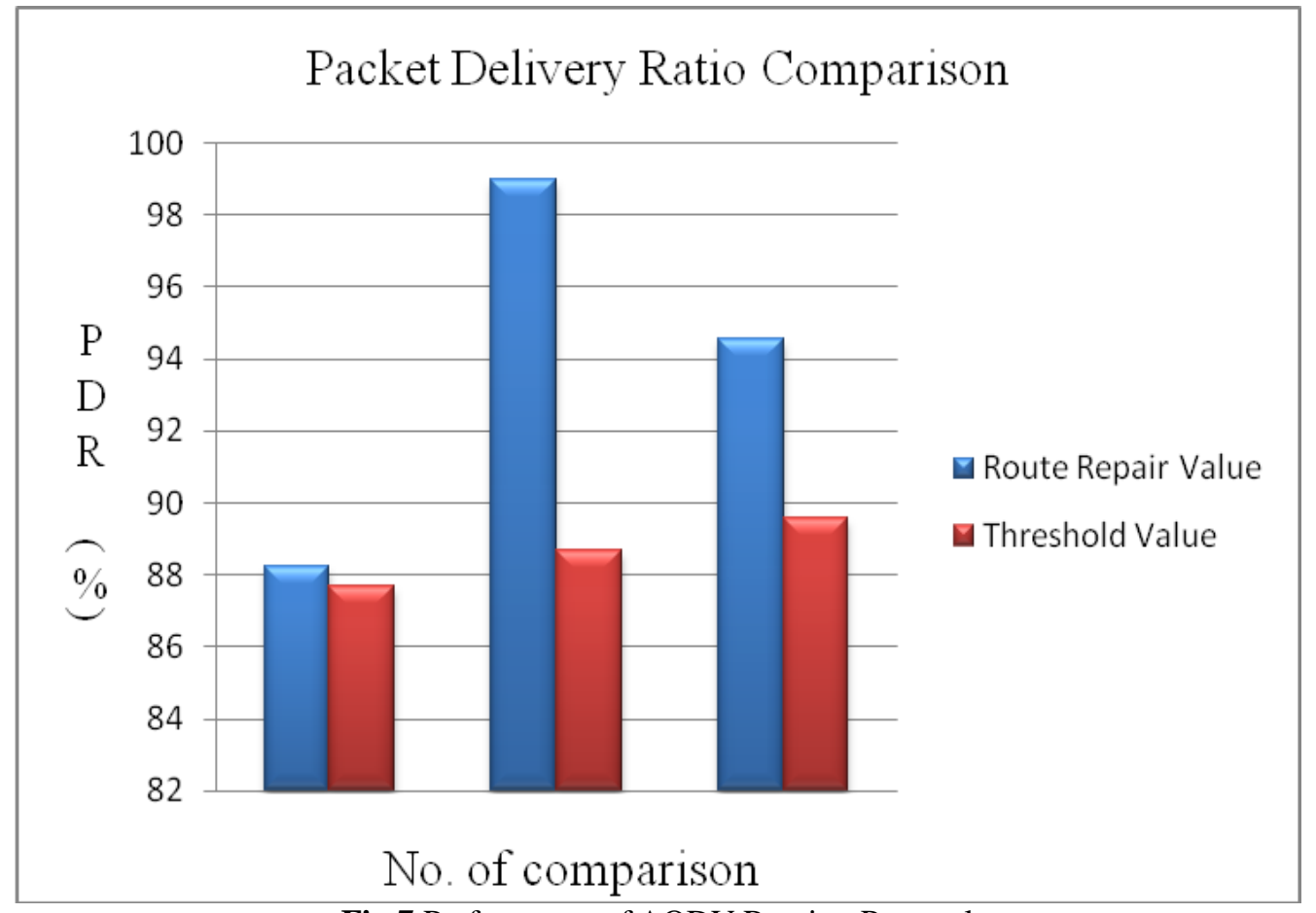

Fig 7 Performance of AODV Routing Protocol

\section{CONCLUSION}

MANET does not provide the guarantee of delivering data packets before the complete execution because the mobile nodes frequently change its topology and leave the network then the active routes are broken from source to destination. Then the routing is one of the major challenging issues in mobile ad-hoc network due to its variable nature. In this research work, we make a study about the route repair techniques for routing protocol in highly dynamic nature of mobile ad-hoc networks. Define the different network scenarios for simulation, where some mobile nodes change their positions due to the node mobility. Then find out the link break value of the network and define the different route repair values on the basis of the active path of the network for estimating which route repair technique is used. Different route repair value is used for each scenario for the selection of route repair mechanism and finds the optimal result of route repair techniques.

Implementation and result analysis section clearly identify that which route repair techniques are used in the different cases of link break.

AODV supports two route repair approaches such as source repair or local repair. Either the routes can be repaired by reestablishing a new route starting from the source node is the source repair approach or the routes can be repaired by the node that detects the link break along the path is the local repair approach.

\section{REFERENCES}

[1] M. Uddin, A. A. Rahman and A. Alarifi Muhammad Talha, "Improving Performance of Mobile Ad-hoc Networks using Efficient Tactical On - Demand Distance Vector (TAODV) Routing Algorithm," proceeding of International Journal of Innovative Computing, Information and Control, Volume 8, November 6, June 2012 ISSN: 1349- 4198, pp 43754389

[2] Dr. S. S. Dhenakaran and A. Parvathavarthini, "An Overview of Routing Protocols in Mobile Ad-hoc Network," proceeding of International Journal of Advanced Research in Computer Science and Software Engineering, Volume 3, Issue 2, February 2013, ISSN: 2277-128X, pp. 251-259

[3] Imrich Chlamtac, Marco Conti and Jennifer J. N. Liu, "Mobile Ad-hoc Networking: Imperatives and Challenges," proceeding of Science Direct Ad-hoc Networks 1, (2003) pp. 13-64

[4] Mohit Kumar and Rashmi Mishra, "An overview of MANET: History, Challenges and Applications," proceeding of Indian Journal of Computer Science and Engineering, Volumes 3, No. 1, Feb-Mar 2012, ISSN: 0976-5166, pp. 121-125.

[5] Sunil Taneja and Ashwani Kush, "A Survey of Routing Protocols in Mobile Ad-hoc Networks," proceeding of International Journal of Innovation, Management and Technology, Volume 1, No. 3, August 2010, ISSN: 2010-0248, pp. 279-285.

[6] G. S. Mamatha and Dr. S C Sharma, "Analyzing the MANET Variations, Challenges Capacity and Protocol Issues," proceeding of the International Journal of, Computer Science and Engineering Survey (IJCSES) Volume 1, No. 1, August 2010, pp. $14-21$ 
[7] B. Soujanya and T. Sitamahalaxmi, "Study of Routing Protocols in Mobile Ad-hoc Networks," proceeding of International Journal of Engineering Science \& Technology, volume 3, No 4, April 2011, pp. 2622-2631, ISSN: 0975-5462.

[8] Jyoti Jain, Roopam Gupta and T. K. Bandhopadhyay, "On Demand Local Link Repair Algorithm for AODV Protocol," proceeding of International Journal of Computer Applications (0975-8887), volume 35, No.5, December 2011. pp. 20-25.

[9] Saaidal R. Azzuhri, Marius Portmann and Wee Lum Tan, "Evaluation of Parameterized Route Repair in AODV," proceeding of IEEE 2010

[10] Asha Ambhaikar, H.R. Sharma and V. K. Mohabey, "Improved AODV Protocol for Solving link failure in MANET," proceeding of International Journal of Scientific and Engineering Research, volume 3, issue 10, October 2012, ISSN: 2229-5518, pp. 1-6. 